\title{
Escrita urbana: a pixação paulistana
}

\section{Alexandre Barbosa Pereira}

Mestre e doutorando em Antropologia Social pela FFLCH/USP e Pesquisador do Núcleo de Antropologia Urbana \{NAU/USP).

Vandalismo, Sujeira e Poluição Visual, definiçóes logo levantadas ao se discutir o que seria esta forma de expressão urbana que é vista por quase toda a paisagem da cidade de São Paulo: a pixação, escrita assim mesmo com " $x$ ", conforme o uso feito pelos próprios pixadores. Fato que poderia sinalizar apenas uma suposta ignorância das regras gramaticais, visto que a grafia correta da palavra seria pichação com “ch", é colocado pelos próprios pixadores como uma maneira de diferenciar a sua prática da definiçáo comum de pichação. Pois o que fazem não é simplesmente pichar um nome, uma palavra ou uma frase qualquer em um muro, mas sim pixar a sua marca desenhada com letras estilizadas, contorcidas e com um formato anguloso.

As marcas que "lançam" nos muros, prédios, viadutos e monumentos da cidade são geralmente nomes de grupos de pixadores. Estes nomes, no entanto, têm pouca importância quando estão inseridos no contexto mais geral da pixação. Os pixadores não se importam muito com o que significa a denominação empregada por determinado grupo, embora esta siga muitas vezes um certo padrão no repertório que é utilizado para nomeá-los, tendo nas idéias de sujeira, marginalidade, transgressão e loucura, temas a que se referem constantemente. Estes jovens, no entanto, dão grande valor ao formato impresso às letras, às figuras que são desenhadas entre as letras e à estilização adotada para se escrever, ou inscrever, aquela pixaçáo na paisagem urbana. Não se pixa de qualquer modo ou com qualquer letra, mas com um formato pré-elaborado, com tipos de letras criadas pelos próprios, demonstrando um padrão estético peculiar. Além disso, há um diálogo com o espaço urbano, com o local onde esta marca será "lançada": é preciso que ela esteja em local de grande destaque na cidade. Obter grande visibilidade é um outro fator que torna uma pixação ainda mais atraente para os pixadores.

Porém, a idéia de que há uma beleza nesta escrita urbana, conforme outra denominação dada às pixaçóes pelos seus próprios autores, não é compartilhada por grande parte dos cidadãos paulistanos, senáo por todos. A pixação é vista pela população e pelo poder público como vandalismo, sujeira e poluição visual, devido, em grande parte, ao desconhecimento da mensagem que ali é transmitida e ao ato em si que é considerado um ataque à propriedade alheia. Por isso, a pixação e os pixadores são vistos como um dos grandes vilóes da cidade. As marcas que eles deixam pelos muros afora são constantemente apagadas e alguns chegam a ser presos ou espancados pela polícia se pegos em ação. Dessa maneira, eles, além de enfrentar o perigo de escalar edifícios e desafiar a polícia, têm de lidar com a efemeridade do suporte em que inserem suas pixaçóes, pois a qualquer momento elas podem ser apagadas. Uma das formas encontradas para solucionar essa questão é a troca das "folhinhas", folhas de papel em que eles inscrevem as marcas que deixam na cidade. Os pixadores trocam estas folhinhas entre si e as colecionam em pastas. Alguns têm verdadeiros acervos de folhinhas em que fixam em um outro suporte suas inscriçóes tão malvistas e efêmeras na cidade. 


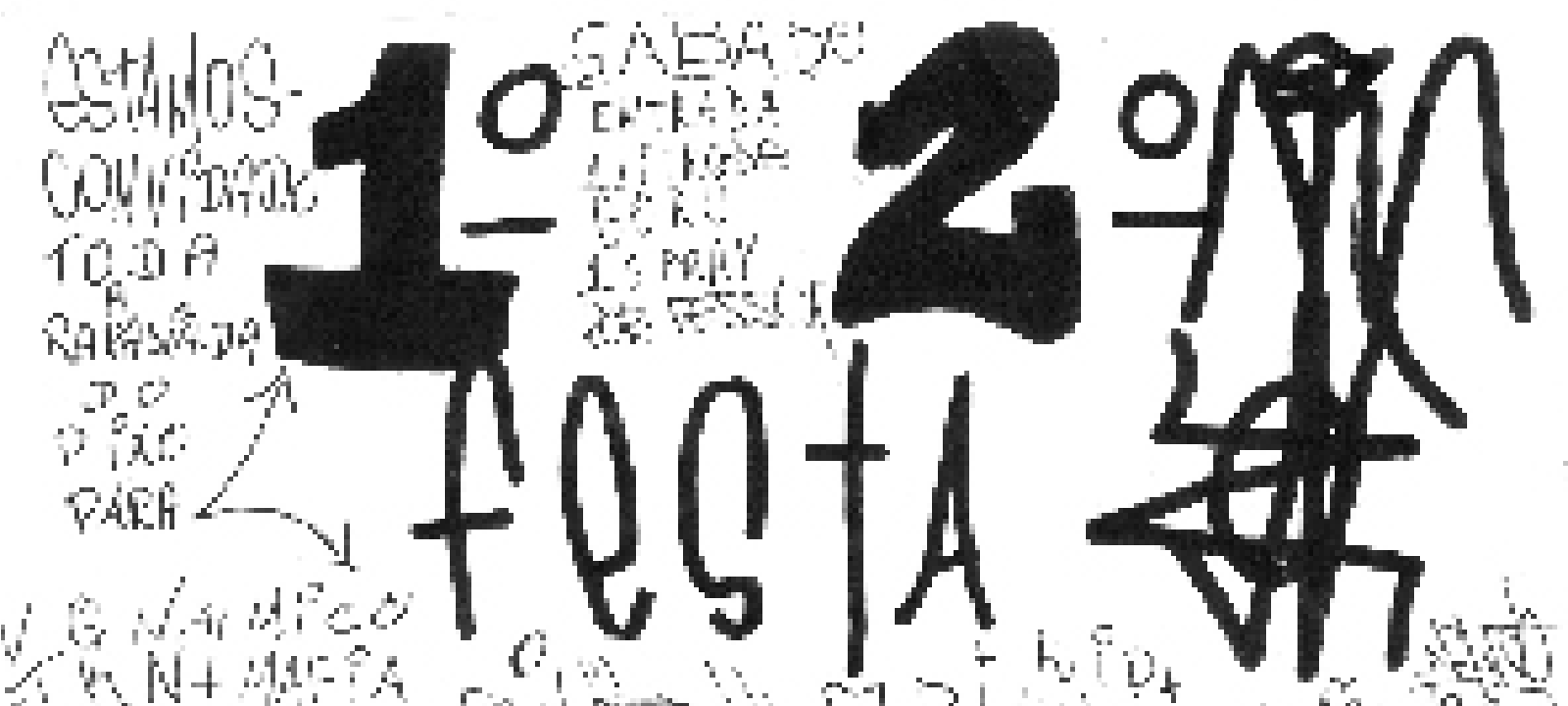

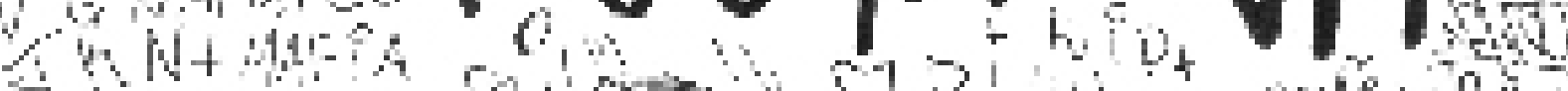

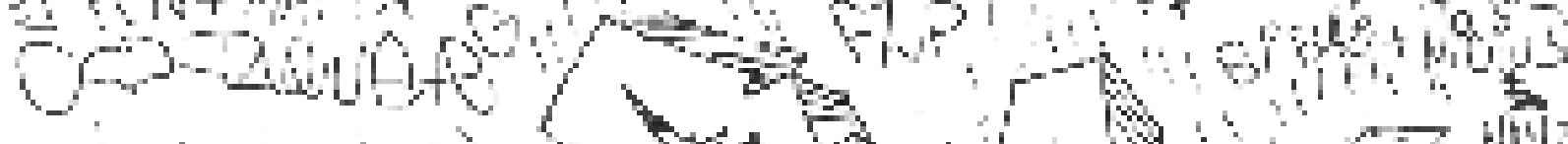
$\Leftrightarrow=0$ Ha

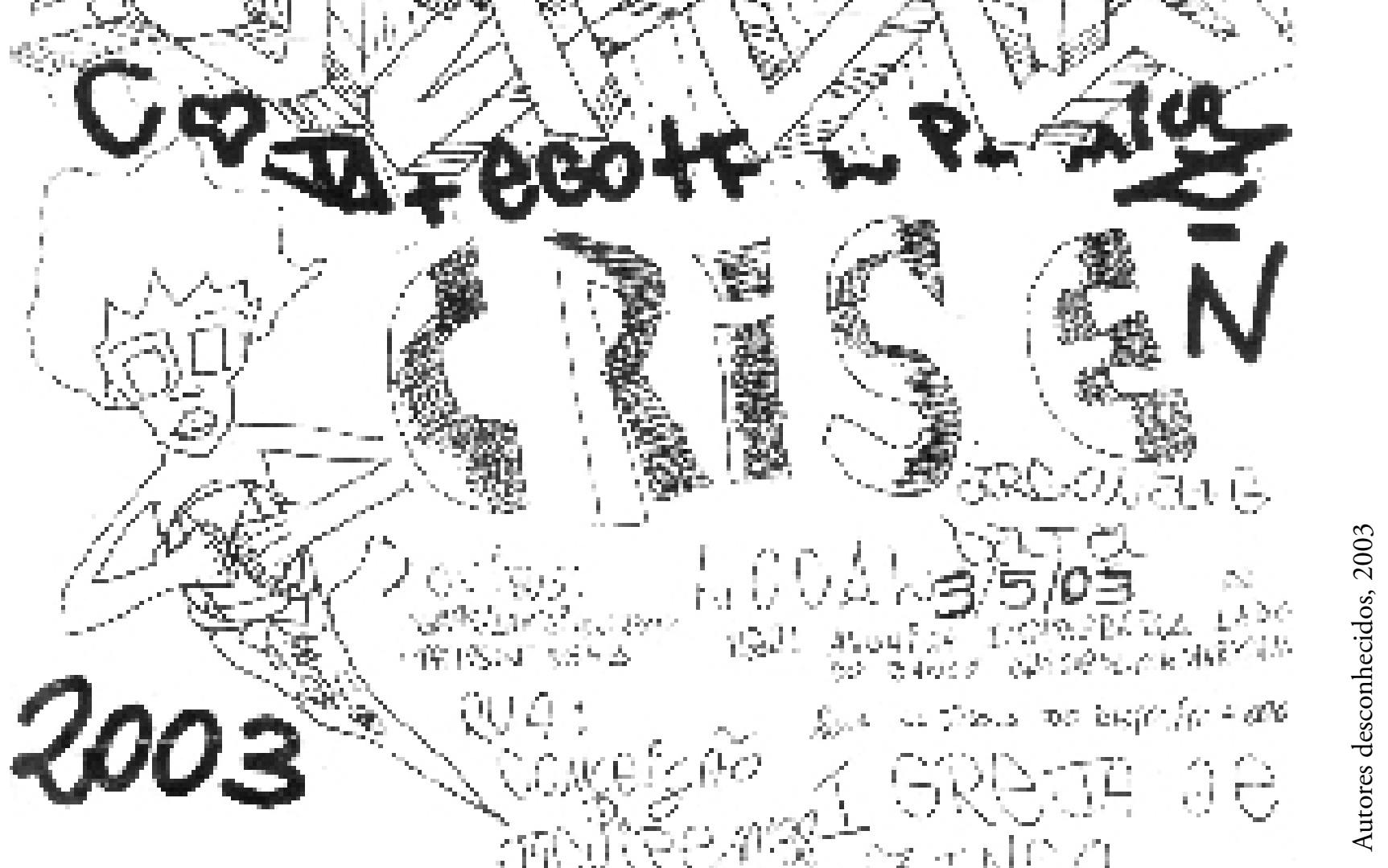


then
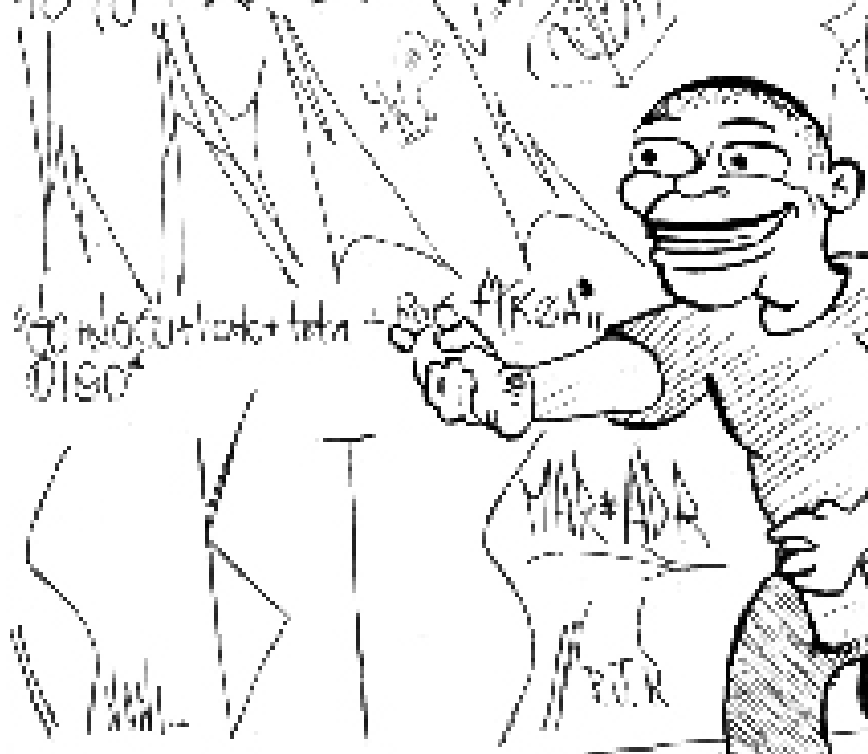

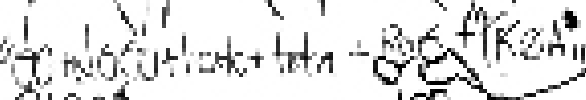
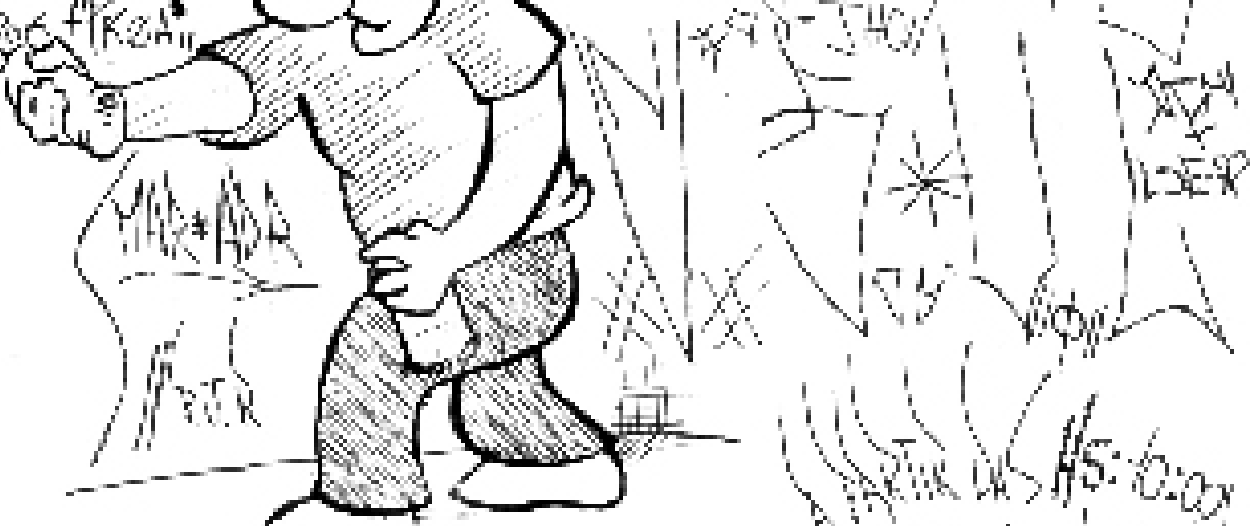

Hon ok

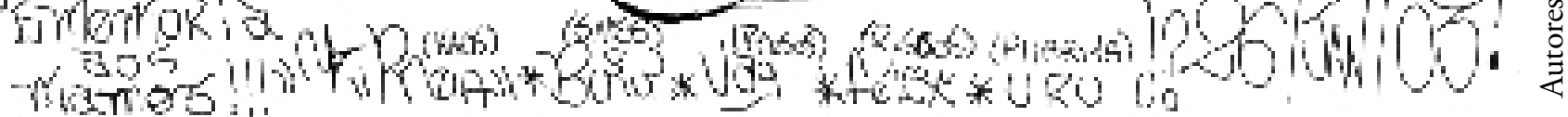

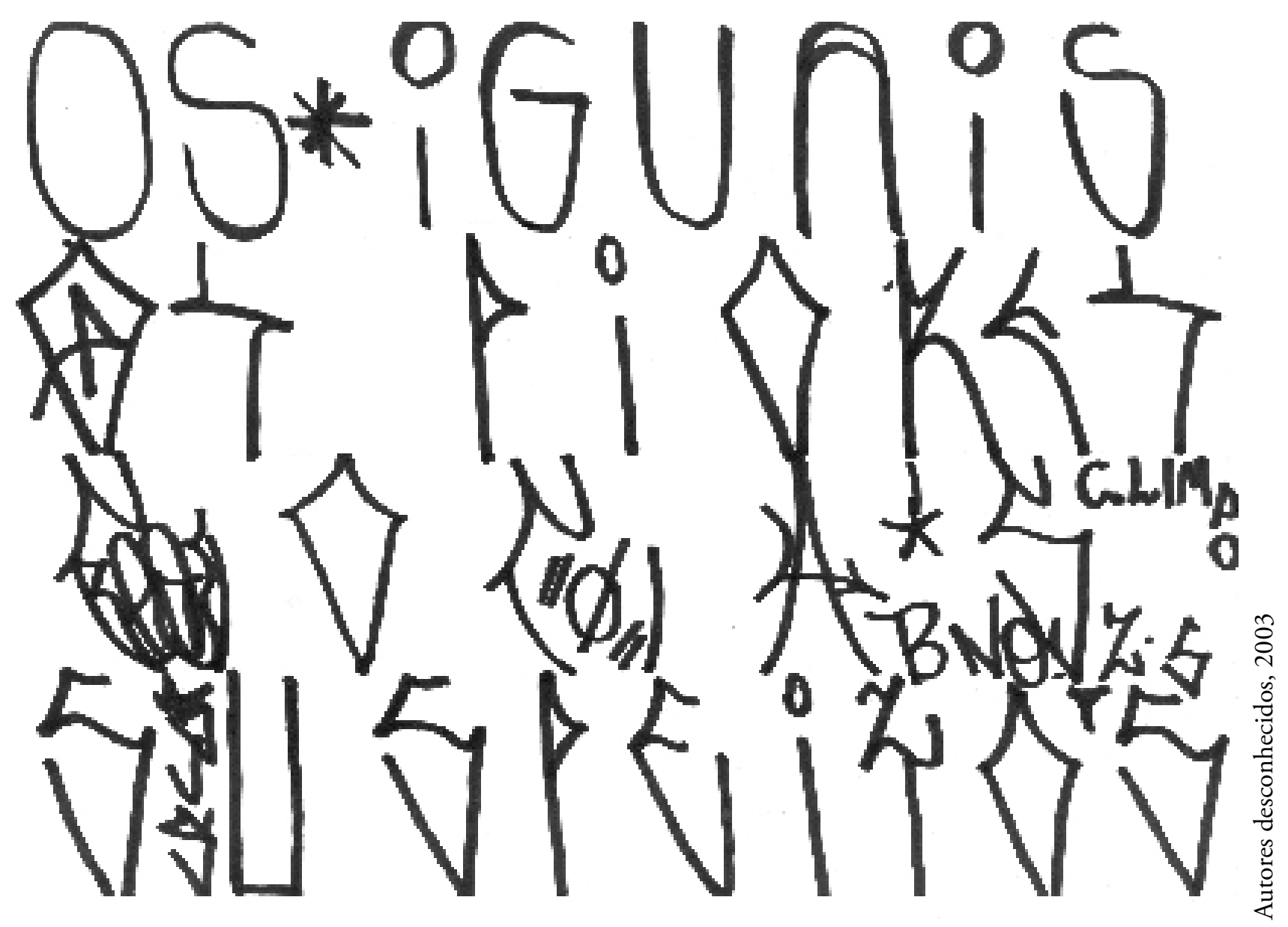




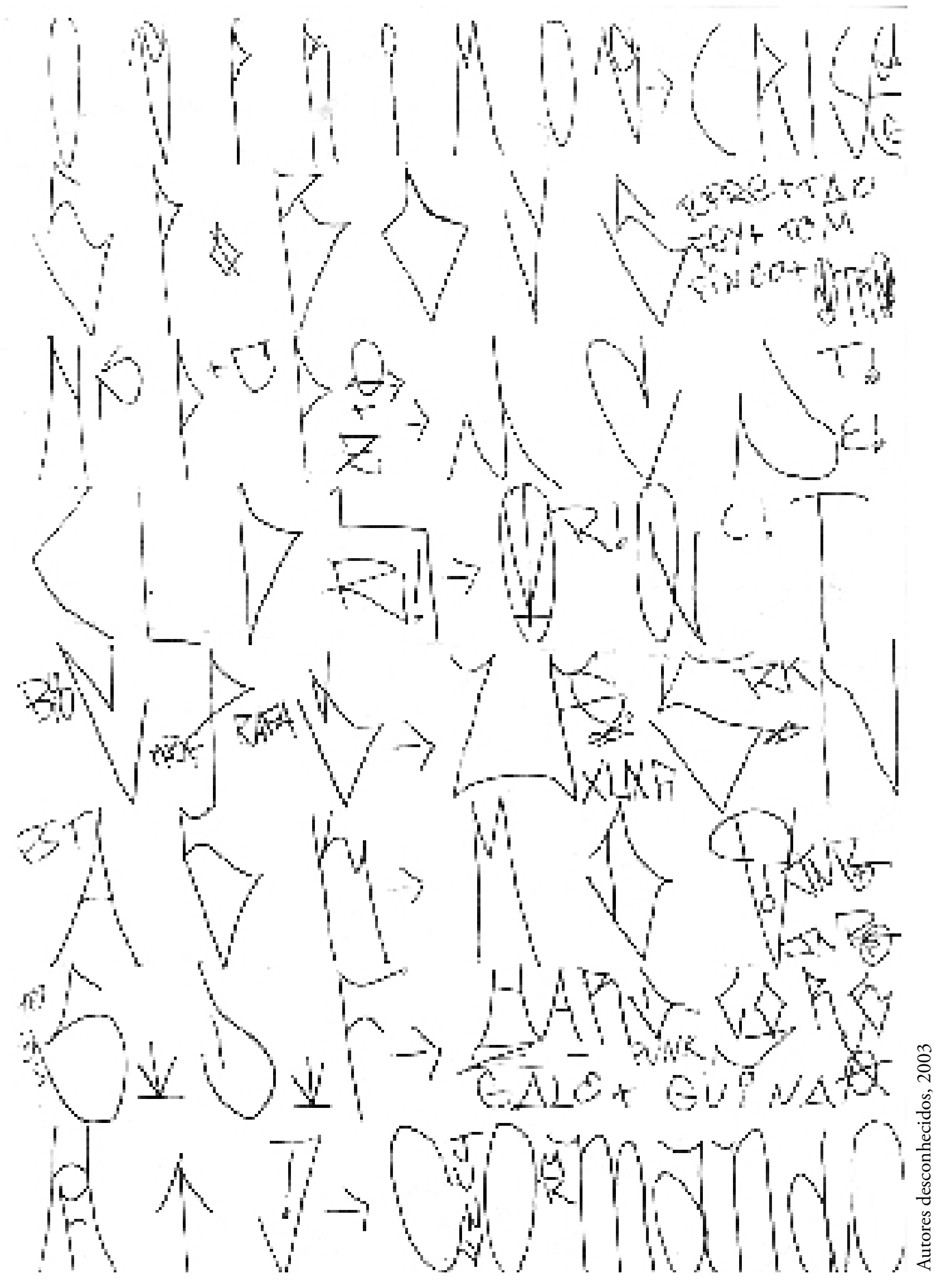

